\title{
The Analysis of External Debt Sustainability by Periodic Unit Root Test with Structural Break: The Case of Turkey
}

\author{
Ozlem Goktas ${ }^{1, *} \&$ Aycan Hepsag ${ }^{1}$ \\ ${ }^{1}$ Department of Econometrics, Faculty of Economics, Istanbul University, Istanbul, Turkey \\ *Correspondence: Department of Econometrics, Faculty of Economics, Istanbul University, \\ Istanbul, Turkey. Tel: 90-212-440-0160. E-mail: ozlemg@istanbul.edu.tr
}

Received: August 6, 2015 Accepted: September 29, 2015 Published: November 9, 2015

doi:10.5296/rae.v7i4.8123 URL: http://dx.doi.org/10.5296/rae.v7i4.8123

\begin{abstract}
The aim of this study is to investigate external debt sustainability using the periodic unit root rest with structural break which is introduced by Boswijk and Franses (1995) and then developed by Evans (2006). In order to test the hypothesis, we use quarterly Turkish data measuring the ratio of external debt stock to GDP that covers the period from the first quarter of 1990 to the third quarter of 2012. The empirical results support that the ratio of external debt stock to GDP has the periodic behavior under structural change and follows a nonstationary periodic process with structural break. According to the empirical findings, it is argued that the external debt is unsustainable in Turkey.
\end{abstract}

Keywords: External Debt Sustainability, Periodic Autoregressive Models, Periodic Unit Root Test with Structural Break 


\section{Introduction}

Developing countries borrow monetary funds from external sources i.e. foreign countries or institutions. External financing often appears more attractive because of smaller crowding out effects on private investment, and reduced risks of inflationary pressure (Waheed, 2005, 201). External debt, which serves the needs of the country to meet the debt-service requirements and reduce the debt rollover risk, is a useful borrowing tool with longer maturity than domestic debt. Although external debt is a useful financing tool, attention should be paid to keep repaying external debt without arrears due to credibility concerns.

Redžepagić and Llorca (2007) remark that there are difficulties in the definition of sustainability and there is no consensus among economists regarding the conditions for sustainability. Debt sustainability is defined as a situation in which a borrower is expected to be able to continue servicing its debts without an unrealistically large future correction to the balance of income and expenditure (IMF, 2002, 4). A country's external debt is qualified as "sustainable" if the present value of its net future foreign earnings is equal to current value of its external debt (Mohammadi et al., 2007, 2442).

The goal of this paper is to investigate external debt sustainability using the periodic unit root test with structural break, which is introduced by Boswijk and Franses (1995) and then developed by Evans (2006). In the empirical studies which use monthly or quarterly data, the first referenced method is to eliminate periodicity (seasonality) by convenient adjustment techniques. However, the adjustment of periodic (or seasonal) behaviors causes a significant loss of valuable information in time series. The present paper differs from the extant literature in the following way: it is the first study that considers periodicity and structural break together on external debt sustainability using the framework of the periodic unit root test with structural break proposed by Boswijk and Franses (1995) and Evans (2006).

The remainder of the paper is organized as follows: in section 2 we provide a literature review and in section 3 we present the econometric methodology. Section 4 contains the data description and empirical results of the study. The fifth and last section includes conclusions.

\section{Literature Review}

According to Roubini (2001), external debt sustainability is measured by three main indicators such as the ratio of external debt to GDP, ratio of external debt to exports and ratio of external debt to government revenues. Roubini (2001) also claims that the ratio of external debt to GDP is a better measure for assessing solvency. If a country's ratio of external debt to GDP does not increase over time, the country tends to remain solvent. Otherwise, increasing ratio of external debt to GDP should be compensated by a larger trade surplus. The satisfaction of intertemporal budget constraint depends on the stationary of external debt. Accordingly, in econometrics methodology, unit root tests provide valuable and important tools for analyzing external debt sustainability.

Within the intertemporal budget constraint approach, Trehan and Walsh (1991) propose a procedure that requires the stationary of the ratio of external debt to GDP for the 
sustainability of the external debt. On the other hand, Hakkio and Rush (1991) suggest an alternative approach to Trehan and Walsh (1991), one which is based on the cointegrating relationship between exports and imports of a country.

The authors who examine external debt sustainability using quarterly data do not consider either the periodic (or seasonal) behaviors of the ratio of external debt to GDP or the other indicators. Instead, they use seasonally adjusted data sets or do not handle deterministic and/or stochastic features of periodicity (or seasonality) in external debt to GDP ratio or the other indicators so the periodic (or seasonal) features of the external debt to GDP ratio are omitted by extant empirical studies.

External debt sustainability is rarely documented on empirical grounds. One of the studies based on the approach of Hakkio and Rush (1991) was conducted by Bahmani-Oskooee and Domac (1995). Bahmani-Oskooee and Domac (1995) investigated the long-run relationship between exports and imports series to test the external debt sustainability of Turkish economy and found that Turkey's external debt was sustainable. On the other hand, Utkulu (1998) investigated the cointegrating relationship between exports and imports series and found empirical evidence supporting that Turkey's external debt was unsustainable.

Önel and Utkulu (2006) explored Turkey's external debt sustainability following the approach of Hakkio and Rush (1991) taking into account the structural break in cointegrating relation between exports and imports series. They concluded that the empirical results that Turkey's external debt was sustainable. In the same vein, the results of Mohammadi et al. (2007) supported the contention that Turkey's external debt was sustainable. Hussain and Idrees (2015) investigated the sustainability of external debt of Pakistan using annual data and found that Pakistan's external debt was sustainable.

Nevertheless, the extant literature contains the studies which are based on the approach developed by Trehan and Walsh (1991). Utkulu (1999) investigated external debt sustainability of the Turkish economy using unit root tests and reported that Turkey's external debt was unsustainable. Yilanci and Özcan (2007) used quarterly data for the ratio of external debt to GDP to investigate external debt sustainability of the Turkish economy. Yilanci and Özcan (2007) applied Threshold Autoregressive (TAR) unit root test to the external debt to GDP ratio and reported Turkey's external debt to be unsustainable. Takeuchi (2010) explored the external debt sustainability of USA using Markov Switching unit root test. He also used the quarterly data in his work and concluded that USA's ratio of the external debt to GDP was unsustainable.

Nasir and Noman (2012) used annual data to investigate external debt sustainability using debt-to-external earnings ratios from 36 countries and current account balance-to-gross national income (GNI) ratios from 55 countries. They applied non-linear ADF unit root test and found strong evidence of non-linearity and sustainability of external debt.

Kiran (2012) examined whether the external debt of Turkey was sustainable or not, using fractional integration approach for annual data. The empirical results of this study displayed that the external debt of Turkey was not sustainable. Lau et al. (2013) explored the external debt sustainability of Asian countries using univariate and panel unit root test for annual data 
and they concluded that debt sustainability was a general characteristic of all the Asian countries.

Schoder et. al. (2013) investigated the external debt sustainability of European Monetary Union Countries using quarterly data and employing univariate and panel unit root tests. They concluded that the external debt was unsustainable in the euro area. Cuestas et al. (2015) applied fractional integration techniques for examining the sustainability of external debt of a group of European countries using quarterly data. They found strong empirical evidence of sustainability of external debt in European countries.

\section{Econometric Methodology}

In this section, we discuss the econometric methodology of the periodic unit root test with structural break which aims to investigate the external debt sustainability of Turkey. The periodic unit root test was firstly introduced by Boswijk and Franses (1995). The periodic unit root test is based on periodic autoregressive (PAR) models. Evans (2006) develops the periodic unit root test of Boswijk and Franses (1995) by including the structural break exogenously in the $P A R$ model. In the framework of periodic unit root test, after the estimation of the $P A R$ model, the presence of periodic behavior of the related time series is determined. If the times series displays periodic behaviors, the presence of periodic unit root would be investigated.

The PAR model is described as an autoregressive model whose parameters are allowed to vary due to seasons. A periodic autoregression of order $p, P A R(p)$ model for a quarterly observed $y_{t}$ series can be expressed in the following form (Boswijk and Franses, 1995, 242):

$$
y_{t}=\sum_{s=1}^{4} \mu_{s} D_{s t}+\sum_{i=1}^{p} \sum_{s=1}^{4} \phi_{i s} D_{s t} y_{t-i}+\varepsilon_{t} \quad t=1, \ldots, N, N=4 n, i=1, \ldots, p
$$

where $\phi_{i s}$ and $\mu_{s}$ denote parameters which vary with seasons $(s=1,2,3,4) . D_{s t}$ and $\varepsilon_{t}$ represent seasonal dummies and the white noise error term, respectively. Trend variable $T_{s t}$ can be added into model (1) as $1,1,1,1,2,2,2,2,3,3,3,3,4,4,4,4, \ldots \ldots$ so $P A R(p)$ model with trend can be represented in the following form (Franses and Paap, 2004, 30):

$$
y_{t}=\sum_{s=1}^{4} \mu_{s} D_{s t}+\sum_{s=1}^{4} \delta_{s} D_{s t} T_{s t}+\sum_{i=1}^{p} \sum_{s=1}^{4} \phi_{i s} D_{s t} y_{t-i}+\varepsilon_{t}
$$

where $\phi_{i s}, \mu_{s}$ and $\delta_{s}$ also denote parameters which vary with seasons $(s=1,2,3,4)$. The estimation of $P A R$ models is done using the Ordinary Least Squares (OLS) method. The determination of order of $\operatorname{PAR}(p)$ model is a crucial issue for the estimation of $P A R$ models. The optimal order $p$ could be selected through the Akaike info criterion (AIC) and Schwarz Criterion (SC) in the following forms (Franses and Paap, 2004, 43): 


$$
\begin{gathered}
A I C(p)=N \log R S S+8 p \\
S C(p)=N \log R S S+4 p \log N
\end{gathered}
$$

where $p$ is the order of PAR model, $N$ is the total number of observations, RSS is the residual sum of squares of $\operatorname{PAR}(p)$ model. Franses and Paap (1994) suggest a convenient strategy; i.e. using Schwarz criterion to obtain a first indication of the lag order of PAR models (Franses and Paap, 2004, 30). PAR models are the general form of AR models whose parameters vary with seasons so one should examine whether the autoregressive parameters of a PAR model exactly indicate periodicity or not. After the estimation of $P A R$ model with appropriate order $p$, Boswijk and Franses (1995) propose a standard $F-$ test to test the periodic variation in autoregressive parameters. For the quarterly data, the non-periodic variation is tested against the periodicity for the null hypothesis $H_{0}: \phi_{i 1}=\phi_{i 2}=\phi_{i 3}=\phi_{i 4} \quad(i=1, \ldots, p) \quad($ del Barrio Castro and Osborn, 2004, 310). The $F$-test for this $H_{0}$, which can be denoted as $F_{P A R}$, has asymptotically an $F_{(3 p, N-(4+4 p)}$ distribution in the case of $\operatorname{PAR}(p)$ process with four seasonal intercepts (Franses and Paap, 2004, 43). The rejection of the null hypothesis displays that $y_{t}$ follows periodic process. Franses (1995) points out that the distribution of this $F$-test is not affected by the stationary properties of $y_{t}$ hence there is no need for testing for seasonal and/or non-seasonal unit roots before the estimation of PAR models. On the other hand, once we estimate the PAR model, we should check whether the error term $\varepsilon_{t}$ conforms the assumptions or not, such as the normality, no autocorrelations at the first order and the first to the fourth orders, no autoregressive conditional heteroskedasticity $(\mathrm{ARCH})$ effect at the first order and the first to the fourth orders.

Boswijk and Franses (1995) propose a periodic unit root test which imposes the restriction as $\phi_{11} \phi_{12} \phi_{13} \phi_{14}=1$ to PAR models shown at (1) and (2). The restricted models are presented in the following forms, respectively:

$$
y_{t}=\sum_{s=1}^{4} \mu_{s} D_{s t}+\sum_{s=1}^{3} \phi_{1 s} D_{s t} y_{t-1}+\left(\phi_{11} \phi_{12} \phi_{13}\right)^{-1} D_{4 t} y_{t-1}+\sum_{i=1}^{p-1} \sum_{s=1}^{4} \psi_{i s} D_{s t}\left(y_{t-i}-\phi_{1 s-1} y_{t-i-1}\right)+\varepsilon_{t}
$$




$$
\begin{aligned}
y_{t}= & \sum_{s=1}^{4} \mu_{s} D_{s t}+\sum_{s=1}^{4} \delta_{s} D_{s t} T_{s t}+\sum_{s=1}^{3} \phi_{1 s} D_{s t} y_{t-1}+\left(\phi_{11} \phi_{12} \phi_{13}\right)^{-1} D_{4 t} y_{t-1} \\
& +\sum_{i=1}^{p-1} \sum_{s=1}^{4} \psi_{i s} D_{s t}\left(y_{t-i}-\phi_{1 s-1} y_{t-i-1}\right)+\varepsilon_{t}
\end{aligned}
$$

where for $s=1, \phi_{1 s-1}$ parameter is $\phi_{10}$ and it is assumed $\phi_{10}=\phi_{14}$. The models (5) and (6) are estimated using Nonlinear Least Squares (NLS) method.

Boswijk and Franses (1995) call (1) and (2) "unrestricted" models and (5) and (6) "restricted" models. Thus, they propose a likelihood ratio test statistic for testing periodic unit root which is based on the residuals sums of squares of "restricted" and "unrestricted" models shown as the following:

$$
L R=\left[\operatorname{sign}\left(\hat{\phi}_{11} \hat{\phi}_{12} \hat{\phi}_{13} \hat{\phi}_{14}-1\right)\right] \sqrt{N \ln \left(\frac{R S S_{R}}{R S S_{U R}}\right)}
$$

where $N$ is the total number of observations, $R S S_{R}$ and $R S S_{U R}$ are the residuals sums of squares of restricted and unrestricted models, respectively. $\hat{\phi}_{11} \hat{\phi}_{12} \hat{\phi}_{13} \hat{\phi}_{14}$ is the product of the estimated parameters of unrestricted model and $\ln$ denotes the natural logarithm. There are three types of the $L R$ test statistic in the framework of periodic unit root test. The first type is shown as $L R$ which denotes that the $P A R$ model has no seasonal dummies and no seasonal trend variables. In the second type, only seasonal dummies are included into the $P A R$ model and this case is shown as $L R_{\mu}$. The third type, which is shown as $L R_{\tau}$, implies that seasonal dummies and seasonal trend variables are included into the $P A R$ model. $L R$ statistics for a unit root in periodic autoregressions have the same asymptotic null distributions as Fuller's (1976) $\hat{\tau}, \hat{\tau}_{\mu}$ and $\hat{\tau}_{\tau}$ statistics (Boswijk and Franses, 1996, 230).

Although it is well known that the possible structural break influences the results of unit roots tests, PAR models shown at (1) and (2) which are proposed by Boswijk and Franses (1995) do not consider structural break in the series $y_{t}$. The null hypothesis of unit root tends to be not rejected because of a possible structural break in the series $y_{t}$. Evans (2006) develops the periodic unit root test with structural break that considers any possible structural break as exogenous in the series.

The approach of Evans (2006) contains two types of models; the first model is similar to Perron's (1989) model A, which detects the possible structural break in the intercept. The second model is similar to Perron's (1989) model C which detects the possible structural break both in the intercept and the trend.

The model which detects the structural break in intercept is obtained by including a shift-type dummy variable in $P A R$ model that is shown at (1):

$$
y_{t}=\sum_{s=1}^{4} \mu_{s} D_{s t}+\sum_{s=1}^{4} \mu_{s}^{\prime} D_{s t} D B_{s t}+\sum_{i=1}^{p} \sum_{s=1}^{4} \phi_{i s} D_{s t} y_{t-i}+\varepsilon_{t}
$$


where $D B_{s t}$ is a shift-type dummy variable that takes on a value of zero before and that quarter of the structural change occurs and value of one thereafter. Model (8), which is estimated using the Ordinary Least Squares (OLS) method, is called the "unrestricted" model as the model shown at model (1). Imposing the restriction of periodic unit root which is given as $\phi_{11} \phi_{12} \phi_{13} \phi_{14}=1$ for the model (8), the "restricted" model is shown as following:

$$
\begin{aligned}
y_{t}= & \sum_{s=1}^{4} \mu_{s} D_{s t}+\sum_{s=1}^{4} \mu_{s}^{\prime} D_{s t} D B_{s t}+\sum_{s=1}^{3} \phi_{1 s} D_{s t} y_{t-1}+\left(\phi_{11} \phi_{12} \phi_{13}\right)^{-1} D_{4 t} y_{t-1} \\
& +\sum_{i=1}^{p-1} \sum_{s=1}^{4} \psi_{i s} D_{s t}\left(y_{t-i}-\phi_{1 s-1} y_{t-i-1}\right)+\varepsilon_{t}
\end{aligned}
$$

where for $s=1, \phi_{1 s-1}$ parameter is $\phi_{10}$ and it is assumed as $\phi_{10}=\phi_{14}$. The model (9) is estimated using Nonlinear Least Squares (NLS) method.

The model which detects the structural break in the intercept and trend is obtained by including a shift-type dummy variable and trend shift variable in $P A R$ model that is shown at (2):

$$
\begin{aligned}
y_{t}= & \sum_{s=1}^{4} \mu_{s} D_{s t}+\sum_{s=1}^{4} \delta_{s} D_{s t} T_{s t}+\sum_{s=1}^{4} \mu_{s}^{\prime} D_{s t} D B_{s t} \\
& +\sum_{s=1}^{4} \delta_{s}^{\prime} D_{s t} D T_{s t}+\sum_{i=1}^{p} \sum_{s=1}^{4} \phi_{i s} D_{s t} y_{t-i}+\varepsilon_{t}
\end{aligned}
$$

where $D B_{s t}$ is a shift-type dummy variable that takes on a value of zero before and that quarter of the structural change occurs and value of one thereafter. $D T_{s t}$ is a trend shift variable that takes on a value of zero before and that quarter of the structural change occurs and value of $T_{s t}$ thereafter. Model (10) is estimated using Ordinary Least Squares (OLS) and this model is also called as "unrestricted" model as the model shown at model (2). Again imposing the restriction of periodic unit root which is given as $\phi_{11} \phi_{12} \phi_{13} \phi_{14}=1$ for the model (9), the "restricted" model is shown as following:

$$
\begin{aligned}
y_{t}= & \sum_{s=1}^{4} \mu_{s} D_{s t}+\sum_{s=1}^{4} \delta_{s} D_{s t} T_{s t}+\sum_{s=1}^{4} \mu_{s}^{\prime} D_{s t} D B_{s t}+\sum_{s=1}^{4} \delta_{s}^{\prime} D_{s t} D T_{s t}+\sum_{s=1}^{3} \phi_{1 s} D_{s t} y_{t-1}+ \\
& \left(\phi_{11} \phi_{12} \phi_{13}\right)^{-1} D_{4 t} y_{t-1}+\sum_{i=1}^{p-1} \sum_{s=1}^{4} \psi_{i s} D_{s t}\left(y_{t-i}-\phi_{1 s-1} y_{t-i-1}\right)+\varepsilon_{t}
\end{aligned}
$$

where for $s=1, \phi_{1 s-1}$ parameter is $\phi_{10}$ and it is assumed as $\phi_{10}=\phi_{14}$. The model (10) is estimated using Nonlinear Least Squares (NLS) method.

After estimating the unrestricted model (8) and restricted model (9), the null hypothesis of periodic unit root with structural break is tested by the $L R$ test statistic shown at (7). Evans (2006) states that $L R$ test statistic has the same asymptotic null distribution as Perron's (1989) model A that considers the structural break only in intercept. On the other hand, with the estimation of the unrestricted model (10) and the restricted model (11), the null hypothesis of periodic unit root with structural break is tested also by the $L R$ test statistic 
shown at (7). Evans (2006) also states that this $L R$ test statistic has the same asymptotic null distribution as Perron's (1989) model C that considers the structural break both in intercept and trend.

\section{Data and Empirical Results}

In this section, we investigate the external debt sustainability of Turkey using periodic unit root test with structural break over the period from the first quarter of 1990 to the third quarter of 2012. The data set includes the ratio of external debt to GDP (Debt/GDP). The external debt stock data is obtained from the Central Bank of Republic of Turkey Electronic Delivery Data System. The data on GDP is obtained from the International Financial Statistics (IFS).

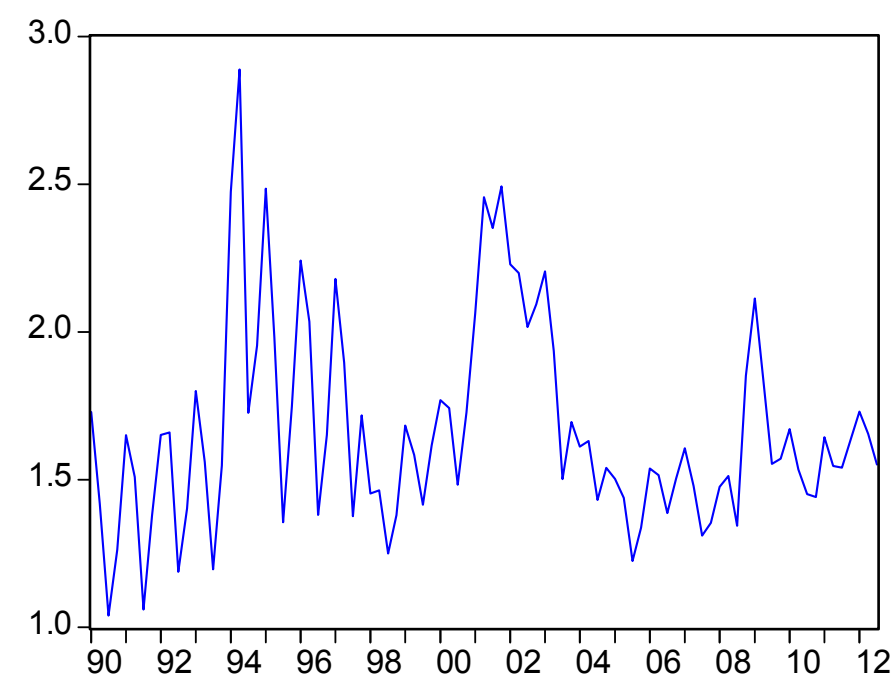

Figure 1. The Graph of the Ratio of External Debt to GDP

As seen at Figure 1, firstly we determine the structural break date exogenously as the first quarter of 1994, when the Turkish economy had an economic crisis. The economic crisis described as a currency crisis that occurred at the first quarter of 1994 affected most of the major macroeconomic indicators as well as the external debt stock and GDP. After detecting the structural break date exogenously as the first quarter of 1994, we determine the optimal lag-lengths as "3" $(p=3)$ for both of the models (8) and (10) through the Schwarz Criterion (SC). In empirical analysis, we call the unrestricted model (8) as unrestricted model A and unrestricted model (10) as unrestricted model $\mathrm{C}$ that considers the structural break in intercept and structural break both in intercept and trend, respectively. The estimation results of model unrestricted model $\mathrm{A}$, unrestricted model $\mathrm{C}$ and the results of the diagnostic tests that belong to these models are reported at Table 1 and Table 2, respectively. 
Table 1. The Estimation Results of Unrestricted Model A and Unrestricted Model C

\begin{tabular}{|c|c|c|c|c|}
\hline \multirow[b]{2}{*}{ Parameters } & \multicolumn{2}{|c|}{ Unrestricted Model A } & \multicolumn{2}{|c|}{ Unrestricted Model C } \\
\hline & Coefficients & t-Statistics & Coefficients & t-Statistics \\
\hline$\mu_{1}$ & 0.56918 & $2.35592 *$ & 0.00950 & 0.02565 \\
\hline$\mu_{2}$ & 0.14068 & 0.53382 & 0.30486 & 0.64735 \\
\hline$\mu_{3}$ & 0.34355 & 1.30004 & -0.08541 & -0.18025 \\
\hline$\mu_{4}$ & 0.25951 & 0.94669 & 0.26899 & 0.77688 \\
\hline$\delta_{1}$ & - & - & 0.19180 & $2.27676^{*}$ \\
\hline$\delta_{2}$ & - & - & -0.03064 & -0.23338 \\
\hline$\delta_{3}$ & - & - & 0.05873 & 0.44699 \\
\hline$\delta_{4}$ & - & - & 0.03548 & 0.42657 \\
\hline$\mu_{1}^{\prime}$ & -0.19472 & -1.58184 & 0.52324 & 1.39639 \\
\hline$\mu_{2}^{\prime}$ & 0.13632 & 1.03176 & 0.12228 & 0.27403 \\
\hline$\mu_{3}^{\prime}$ & 0.13830 & 1.06051 & 0.04050 & 0.09061 \\
\hline$\mu_{4}^{\prime}$ & -0.04738 & -0.38513 & 0.18263 & 0.62338 \\
\hline$\delta_{1}^{\prime}$ & - & - & -0.19448 & $-2.26109^{*}$ \\
\hline$\delta_{2}^{\prime}$ & - & - & 0.02484 & 0.18822 \\
\hline$\delta_{3}^{\prime}$ & - & - & -0.04059 & -0.30729 \\
\hline$\delta_{4}^{\prime}$ & - & - & -0.04631 & -0.55017 \\
\hline$\phi_{11}$ & 1.16757 & $3.19284^{*}$ & 1.01885 & $2.64763^{*}$ \\
\hline$\phi_{12}$ & 0.95194 & $5.39943^{*}$ & 0.90529 & $4.67429^{*}$ \\
\hline$\phi_{13}$ & 0.86442 & $4.12600^{*}$ & 0.93041 & $4.45251^{*}$ \\
\hline$\phi_{14}$ & 0.73895 & $3.01034^{*}$ & 0.85746 & $3.05526^{*}$ \\
\hline$\phi_{21}$ & -0.73554 & $-2.11572 *$ & -0.64027 & -1.52100 \\
\hline$\phi_{22}$ & 0.05148 & 0.12013 & -0.00672 & -0.01551 \\
\hline$\phi_{23}$ & -0.66200 & $-2.51806^{*}$ & -0.52958 & $-1.96182^{*}$ \\
\hline$\phi_{24}$ & 0.14496 & 0.52102 & 0.00504 & 0.01600 \\
\hline$\phi_{31}$ & 0.33678 & 1.90503 & 0.32993 & 1.41953 \\
\hline$\phi_{32}$ & -0.23058 & -0.63129 & -0.15256 & -0.39861 \\
\hline$\phi_{33}$ & 0.42167 & $2.09061^{*}$ & 0.36493 & 1.81913 \\
\hline \multirow[t]{2}{*}{$\phi_{34}$} & 0.05090 & 0.21093 & 0.04153 & 0.17457 \\
\hline & \multicolumn{2}{|c|}{$R S S_{U R, A}=\mathbf{2 . 3 9 6 1 8}$} & \multicolumn{2}{|c|}{$R S S_{U R, C}=\mathbf{2 . 0 4 6 5 7}$} \\
\hline
\end{tabular}

Note: $*$ denotes statistically significance at the $5 \%$ level. 
Table 2. The Results of Diagnostic Tests of Model A and Model C

\begin{tabular}{ccc}
\hline & Unrestricted Model A & Unrestricted Model C \\
\hline$F_{A R, 1}$ & $1.70619^{*}$ & $0.00167^{*}$ \\
& $(0.19595)$ & $(0.96751)$ \\
$F_{A R, 1-4}$ & $2.14234^{*}$ & $3.18256^{* *}$ \\
$F_{A R C H, 1}$ & $(0.08570)$ & $(0.01998)$ \\
$F_{A R C H, 1-4}$ & $3.21518^{*}$ & $0.81074^{*}$ \\
$F_{P A R}$ & $(0.07651)$ & $(0.37044)$ \\
& $0.86892^{*}$ & $0.68175^{*}$ \\
Kolmogorov-Smirno & $(0.48644)$ & $(0.60666)$ \\
& $5.17383^{* * *}$ & $3.69476^{* * *}$ \\
& $(0.00000)$ & $(0.00087)$ \\
& $0.87800^{*}$ & $0.97200^{*}$ \\
\hline
\end{tabular}

Notes: * denotes that the null hypothesis cannot be rejected at $5 \%$ significance level. $* *$ denotes that the null hypothesis cannot be rejected at $1 \%$ significance level. *** denotes the rejection of the null hypothesis at $5 \%$ significance level.

Once estimating the unrestricted model $\mathrm{A}$ and unrestricted model $\mathrm{C}$, the null hypothesis of $H_{0}: \phi_{i 1}=\phi_{i 2}=\phi_{i 3}=\phi_{i 4} \quad(i=1,2,3,4)$ is tested by $F_{P A R}$ test for the determination of periodic variation. According to the results of the $F_{P A R}$ test, the null hypothesis of no periodic variation is rejected for both the unrestricted model $\mathrm{A}$ and the unrestricted model $\mathrm{C}$ at $5 \%$ significance level, which means the external debt stock to GDP ratio has the periodic behavior under the structural change. On the other hand, for the unrestricted model A, the results of $F_{A R, 1}$ and $F_{A R, 1-4}$ tests display that there exists no autocorrelation at the first and at the first to the fourth orders, respectively. For the unrestricted model $\mathrm{C}$, the result of $F_{A R, 1}$ test displays that there exists no autocorrelation at the first order at 5\% significance level, the results of $F_{A R, 1-4}$ test also display there exists no autocorrelation at the first to fourth orders at $1 \%$ significance level.

The results of $F_{A R C H, 1}$ and $F_{A R C H, 1-4}$ tests also show that there exist no autoregressive conditional heteroskedasticity $(\mathrm{ARCH})$ effect at the first order and at the first to the fourth orders, respectively at 5\% significance level for the both the unrestricted model $\mathrm{A}$ and unrestricted model C. Lastly, unrestricted model A and unrestricted model C satisfy the assumption of normality in residuals via Kolmogorov-Simirnov normality test at $5 \%$ significance level. In addition to these results, the residuals sums of squares of unrestricted model A $\left(R S S_{U R, A}\right)$ and the residuals sums of squares unrestricted model $\mathrm{C}\left(R S S_{U R, C}\right)$ are estimated as the values of 2.39618 and 2.04657 , respectively. 
Subsequently, we examine the periodic unit root by imposing the restriction $\phi_{11} \phi_{12} \phi_{13} \phi_{14}=1$ and we estimate models (9) and (11) using Nonlinear Least Squares (NLS) method. With the restriction of $\phi_{11} \phi_{12} \phi_{13} \phi_{14}=1$, we call the model (9) as restricted model A and the model (11) as restricted model $\mathrm{C}$. The results of estimated restricted model $\mathrm{A}$ and restricted model $\mathrm{C}$ are given at Table 3 .

As seen at Table 3, the residuals sums of squares of restricted model A $\left(R S S_{R, A}\right)$ and the residuals sums of squares of restricted model C $\left(R S S_{R, C}\right)$ are estimated as the values of 2.42182 and 2.07052 , respectively.

Table 3. The Estimation Results of Restricted Model A and Restricted Model C

\begin{tabular}{|c|c|c|c|c|}
\hline \multirow[b]{2}{*}{ Parameters } & \multicolumn{2}{|c|}{ Restricted Model A } & \multicolumn{2}{|c|}{ Restricted Model C } \\
\hline & Coefficients & t-Statistics & Coefficients & t-Statistics \\
\hline$\mu_{1}$ & 0.65271 & $2.96105^{*}$ & 0.10611 & 0.30231 \\
\hline$\mu_{2}$ & 0.19519 & 0.76499 & 0.33903 & 0.72439 \\
\hline$\mu_{3}$ & 0.33582 & 1.27406 & -0.09487 & -0.20076 \\
\hline$\mu_{4}$ & 0.27300 & 0.99951 & 0.26807 & 0.77613 \\
\hline$\delta_{1}$ & - & - & 0.19657 & $2.34444^{*}$ \\
\hline$\delta_{2}$ & - & - & -0.02493 & -0.19058 \\
\hline$\delta_{3}$ & - & - & 0.05805 & 0.44289 \\
\hline$\delta_{4}$ & - & - & 0.03540 & 0.42659 \\
\hline$\mu_{1}^{\prime}$ & -0.15746 & -1.37088 & 0.59737 & 1.64462 \\
\hline$\mu_{2}^{\prime}$ & 0.16230 & 1.26495 & 0.15433 & 0.34799 \\
\hline$\mu_{3}^{\prime}$ & 0.13518 & 1.03904 & 0.03465 & 0.07772 \\
\hline$\mu_{4}^{\prime}$ & -0.04165 & -0.33971 & 0.18286 & 0.62567 \\
\hline$\delta_{1}^{\prime}$ & - & - & -0.20107 & $-2.35333^{*}$ \\
\hline$\delta_{2}^{\prime}$ & - & - & 0.02038 & 0.15488 \\
\hline$\delta_{3}^{\prime}$ & - & - & -0.03999 & -0.30347 \\
\hline$\delta_{4}^{\prime}$ & - & - & -0.04633 & -0.55170 \\
\hline$\phi_{11}$ & 0.60283 & $3.81890^{*}$ & 0.60685 & $4.20977 *$ \\
\hline$\phi_{12}$ & 0.15383 & 1.62005 & 0.16760 & 1.57201 \\
\hline$\phi_{13}$ & 14.85070 & 1.00576 & 11.39918 & 1.06324 \\
\hline$\psi_{11}$ & 0.68674 & 1.67796 & 0.42673 & 1.02538 \\
\hline$\psi_{12}$ & 0.77219 & $3.75953^{*}$ & 0.71627 & $3.22970^{*}$ \\
\hline$\psi_{13}$ & -13.98545 & -0.94661 & -10.46797 & -0.97576 \\
\hline$\psi_{14}$ & -0.01114 & -0.69196 & -0.00044 & -0.01688 \\
\hline$\psi_{21}$ & -0.38121 & -1.46318 & -0.33270 & -1.18688 \\
\hline$\psi_{22}$ & 0.63115 & 1.54089 & 0.57823 & 1.42961 \\
\hline$\psi_{23}$ & -2.81915 & $-2.51113^{*}$ & -2.29333 & $-2.67628^{*}$ \\
\hline \multirow[t]{2}{*}{$\psi_{24}$} & -0.00289 & -0.16904 & -0.00373 & -0.17210 \\
\hline & \multicolumn{2}{|c|}{$R S S_{R, A}=\mathbf{2 . 4 2 1 8 2}$} & \multicolumn{2}{|c|}{$R S S_{R, C}=\mathbf{2 . 0 7 0 5 2}$} \\
\hline
\end{tabular}

Note: * denotes statistically significance at the $5 \%$ level. 
Next, we calculate the $L R$ test statistic shown at (7) using $R S S_{R, A}$ and $R S S_{U R, A}$ for model A. We obtain $\hat{\phi}_{11} \hat{\phi}_{12} \hat{\phi}_{13} \hat{\phi}_{14}$, which is the product of estimated parameters of unrestricted model A, as 0.70996 so the value of sign function is found as negative. On the other hand, we also calculate $L R$ test statistic shown at (7) using $R S S_{R, C}$ and $R S S_{U R, C}$ for model C and we also obtain $\hat{\phi}_{11} \hat{\phi}_{12} \hat{\phi}_{13} \hat{\phi}_{14}$, which is the product of estimated parameters of unrestricted model $\mathrm{C}$, as 0.73584 so the value of sign function is found to be negative. The results of the periodic unit root test with structural break of model A and model $\mathrm{C}$ are shown at Table 4.

Table 4. The Results of Periodic Unit Root Test with Structural Break

\begin{tabular}{ccc}
\hline & Model A & Model C \\
\hline LR & $-0.98415^{*}$ & $-1.02895^{*}$ \\
$\lambda$ & -3.77 & -3.99 \\
Critical Values $(5 \%)$ & 0.2 & 0.2 \\
\hline
\end{tabular}

Notes: * denotes the null hypothesis of periodic unit root with structural break cannot be rejected at $5 \%$ level. $\lambda=n_{s t} / n=5 / 23=0.2173 \cong 0.2, n_{s t}$ denotes the observation value of the quarter that occurs the structural break. The critical values are taken from Perron (1989).

The results reported at Table 4 display that the null hypothesis of the periodic unit root test with structural break cannot be rejected for either model A or model $\mathrm{C}$ at the $5 \%$ significance level. Therefore, it is argued that the Debt/GDP variable has a periodic unit root with structural break and the Debt/GDP variable follows nonstationary periodic process. The empirical findings support that there is no evidence of sustainability in the external debt of Turkey.

\section{Conclusions}

In the present paper, we investigate the external debt sustainability of Turkey using periodic unit root test with structural break proposed by Evans (2006) over the period from the first quarter of 1990 to the third quarter of 2012. We assume the ratio of external debt stock to GDP $(D e b t / G D P)$ to be an indicator of the external debt sustainability. The paper presents that $D e b t / G D P$ variable follows nonstationary periodic process with structural break. Accordingly, we conclude that the external debt is unsustainable in Turkey. Furthermore, Debt/GDP variable exhibits periodic behavior under structural break. The unsustainable external debt of Turkey indicates that the monetary and fiscal policies are ineffective. As such, Turkey as a debtor country is likely to be insolvent and does not satisfy the intertemporal budget constraint. For the providing the solvency and hence the sustainability, one of the political choices should be to increase the trade surplus, but Turkish economy has been facing persistent trade deficit since 1950. Turkey should reduce its foreign dependency 
and improve the production possibilities. This way, Turkey could increase its exports capacity and develop a sustainable external debt strategy.

On the other hand, the private sector's share of total external debt stock has been increasing rapidly in the last twenty years. The share of the private sector to total external debt stock was about $20 \%$ in 1990 , yet it reached $70 \%$ in 2012 . The share of the public sector to total external debt stock decreased rapidly in the last twenty years. The share of public sector was about $70 \%$, but it declined to $30 \%$ as of 2012 . It can be argued that the main reason of the unsustainable external debt of Turkey is the external debt stock of private sector. In addition to providing a sustainable external debt, institutional debt management should be constituted in cooperation with the public and private sectors for the reducing of external debt stock of private sector.

\section{References}

Bahmani-Oskooee, M., \& Domac, I. (1995). The Long-Run Relation between Imports and Exports in an LDC: Evidence from Turkey. METU Studies in Development, 22, 177189.

Boswijk, H.P., \& Franses, P.H. (1995). Testing for Periodic Integration. Economic Letters, 48, 241-248. http://dx.doi.org/10.1016/0165-1765(94)00635-F

Boswijk, H.P., \& Franses, P.H. (1996). Unit Roots in Periodic Autoregressions. Journal of Time Series Analysis, 17, 221-245. http://dx.doi.org/10.1111/j.1467-9892.1996.tb00274.x

Cuestas, J.C., Gil-Alana, L.A., \& Regis, P.J. (2015). The Sustainability of European External Debt: What have We Learned?. Review of International Economics, 23, 445-468. http://dx.doi.org/10.1111/roie.12175

del Barrio Castro, T.. \& Osborn, D.R. (2004). The Consequences of Seasonal Adjustment for Periodic Autoregressive Processes. Econometrics Journal, 7, 307-321. http://dx.doi.org/10.1111/j.1368-423X.2004.00132.x

Evans, M. (2006). A Study of the Relationship between Regional Ferrous Scrap Prices in the USA, 1958-2004. Resources Policy, 31, 65-77. http://dx.doi.org/10.1016/j.resourpol.2006.06.001

Franses, P.H. (1995). The Effects of Seasonally Adjusting a Periodic Autoregressive Process. Computational Statistics and Data Analysis, 19, 683-704. http://dx.doi.org/10.1016/0167-9473(94)00019-F

Franses, P.H., \& Paap, R. (1994). Model Selection in Periodic Autoregressions. Oxford Bulletin of Economics and Statistics, 56, 421-439. http://dx.doi.org/10.1111/j.1468-0084.1994.tb00018.x

Franses, P.H., \& Paap, R. (2004). Periodic Time Series Models. Oxford University Press, New York, USA. 
Fuller, W.A. (1976). Introduction to Statistical Time Series. John Wiley, New York, USA.

Hakkio, C.S., \& Rush, M. (1991). Is the Budget Deficit Too Large?”. Economic Inquiry, 29, 429-445.

Hussain, A., \& Idrees, A.S. (2015). Fiscal Performance and External Public Debt Sustainability: A Case Study of Pakistan. Journal of Economics and Sustainable Development, 6, 142-149.

International Monetary Fund. (2002). Assessing sustainability. Policy Department and Review Department. Washington, USA.

Kiran, B. (2012). The Sustainability of Turkish External Debt: Evidence from Fractionally Integrated Approach under Structural Breaks. Ekonomska istraživanja, 25, 21-33.

Lau, E., Baharumshah, A.Z., \& Soon, S. (2013). The Behavior of External Debt in Asian Countries: Evidence Based on Panel Unit Root Tests. Journal of Business Economics and Management, 14, 377-394. http://dx.doi.org/10.3846/16111699.2012.720589

Mohammadi, H., Cak, M., \& Cak, D. (2007). Capital Mobility and Foreign Debt Sustainability: Some Evidence from Turkey. Applied Economics, 39, 2441-2449. http://dx.doi.org/10.1080/00036840600707274

Nasir, A., \& Noman, A.M. (2012). Sustainability of External Debt: Further Evidence from Non-Linear Framework. International Review of Applied Economics, 26, 673-685. http://dx.doi.org/10.1080/02692171.2012.665853

Önel, G., \& Utkulu, U. (2006). Modeling the Long-Run Sustainability of Turkish External Debt with Structural Changes. Economic Modelling, 23, 669-682. http://dx.doi.org/10.1016/j.econmod.2006.03.006

Perron, P. (1989). The Great Crash, the Oil Price Shock and the Unit Root Hypothesis. Econometrica, 57, 1361-1401. http://dx.doi.org/10.2307/1913712

Redžepagić, S., \& Llorca, M. (2007). Does Politics Matter in the Conduct of Fiscal Policy? Political Determinants of the Fiscal Sustainability: Evidence from Seven Individual Central and Eastern European Countries (CEEC). Panoeconomicus, 54, 489-500. http://dx.doi.org/10.2298/PAN0704489R

Roubini, N. (2001). Debt Sustainability: How to assess whether a country is insolvent? Stern School of Business, New York University, New York, USA.

Schoder, C., Proaño, C.R., \& Semmler, W. (2013). Are the Current Account Imbalances Between EMU Countries Sustainable? Evidence from Parametric and Non-Parametric Tests. Journal of Applied Econometrics, 28, 1179-1204. http://dx.doi.org/10.1002/jae.2291

Takeuchi, F. (2010). US External Debt Sustainability Revisited: Bayesian Analysis of Extended Markov Switching Unit Root Test. Japan and the World Economy, 22, 98-106. http://dx.doi.org/10.1016/j.japwor.2009.12.001 
Trehan, B., \& Walsh, C.E. (1991). Testing Intertemporal Budget Constraints: Theory and Applications to U.S. Federal Budget and Current Account Deficits. Journal of Money, Credit, and Banking, 23, 206-223. http://dx.doi.org/10.2307/1992777

Utkulu, U. (1998). Are Turkish External Deficits Sustainable? Evidence from the Cointegrating Relationship between Exports and Imports. D.E.U. I.I.B.F. Journal, 13, 119-132.

Utkulu, U. (1999). Is the Turkish External Debt Sustainable? Evidence from Unit Root Testing. Yapı Kredi Economic Review, 10, 55-65.

Waheed, A. (2005). The Behavior of Public External Debt in Pakistan: A Financial Macroeconomic Analysis. Forum of International Development Studies, 28, 201-228.

Yilanci, V., \& Özcan, B. (2007). External Debt Sustainability of Turkey: A Nonlinear Approach. International Research Journal of Finance and Economics, 20, 91-98.

\section{Copyright Disclaimer}

Copyright for this article is retained by the author(s), with first publication rights granted to the journal.

This is an open-access article distributed under the terms and conditions of the Creative Commons Attribution license (http://creativecommons.org/licenses/by/3.0/). 